\title{
Klinik Örneklerden Mycobacterium tuberculosis Saptanmasında Anyplex MTB/NTM Testinin Değerlendirilmesi
}

\section{Evaluation of Anyplex MTB/NTM Test for The Detection of Mycobacterium tuberculosis in Clinical Specimens}

\author{
Alpaslan ALP1 , Zeynep SARIBAŞ ${ }^{1}$ \\ ${ }^{1}$ Hacettepe Üniversitesi Tıp Fakültesi, Tıbbi Mikrobiyoloji Anabilim Dalı, Ankara. \\ ${ }^{1}$ Hacettepe University Faculty of Medicine, Department of Medical Microbiology, Ankara, Turkey.
}

Makale Atıfı: Alp A, Sarıbaş Z. Klinik örneklerden Mycobacterium tuberculosis saptanmasında Anyplex MTB/NTM testinin değerlendirilmesi. Mikrobiyol Bul 2019;53(4):355-363.

\section{ÖZ}

Klinik örneklerden Mycobacterium tuberculosis'in hızlı ve doğru bir şekilde saptanabilmesi, tüberkülozun etkin kontrolündeki en önemli basamaklardan biridir. Tüberkülozun erken ve doğru tanısı, tedavinin mümkün olan en kısa süre içerisinde başlatılabilmesini sağlamaktadır. Altın standart kültür yöntemlerine ek olarak, tüberkülozun erken tanısında hızlı sonuç veren moleküler yöntemlerin de tanı algoritmasına eklenmesi gerekmektedir. Bu nedenle son yıllarda tüberkülozun rutin tanısının yapıldığı laboratuvarlarda moleküler yöntemler önemli bir basamak haline gelmiştir. Bu çalışmanın amacı, rutin moleküler tanı laboratuvarlarında klinik örneklerden M.tuberculosis saptanması amacıyla kullanılmakta olan Anyplex MTB/ NTM testinin (Seegene, Güney Kore) hızlı tanıdaki etkinliğinin araştırılmasıdır. Çalışmada yanı sıra, yurt dışı kökenli ticari kitlere alternatif olabilecek yerli kitler üretebilmek amacıyla tasarlanmış olan primerlerin polimeraz zincir reaksiyonu (PCR) yöntemiyle ön değerlendirilmesinin yapılması hedeflenmiştir. Çalışmaya toplam üç yıllık süre içerisinde, tüberküloz şüphesi bulunan hastalardan elde edilerek laboratuvara gönderilmiş olan 10.652 klinik örnek dahil edilmiştir. Tüm örnekler boyama sonrasında mikroskobik inceleme, kültür ve gerçek zamanlı PCR (Rt-PCR) yöntemleri kullanılarak test edilmiştir. Hasta örneklerinden hazırlanan yaymalar aside dirençli basil varlığı açısından, Kinyoun boyama yöntemi ile boyandıktan sonra mikroskop ile incelenmiştir. Kültür amacıyla, örneklere $\mathrm{N}$-asetil-L-sistein-sodyum hidroksit yöntemi ile homojenizasyon-dekontaminasyon işlemi uygulanmış, MGIT (Mycobacteria Growth Indicator Tube) şişelerine (Becton Dickinson, $A B D$ ) ve Löwenstein-Jensen besiyerine ekim yapılmıştır. Rt-PCR yöntemi ise Anyplex MTB/NTM testi ile gerçekleştirilmiştir. Çalışmanın birinci aşamasında, tüberkülozun moleküler tanısında kullanılan Anyplex MTB/NTM testinin etkinliği, altın standart kültür yöntemiyle karşılaştırılarak değerlendirilmiştir. Bu amaçla seçilen 100 kültür-pozitif örneğe laboratuvar içi tasarımlı PCR yöntemi uygulanmıştır. Toplam 10.652 örneğin 178 (\%1.7)'inde kültürde M.tuberculosis üremesi saptanmıştır. Altın standart kültür yöntemiyle yapılan karşılaştırma sonucunda Anyplex MTB/NTM testinin duyarlılık ve özgüllüğü akciğer kökenli örneklerde sırasıyla \%84 ve \%99, akciğer dışı örneklerde ise sırasılla \%74 ve \%99 olarak bulunmuştur. Çalışmanın ikinci aşamasında ise, kültür sonucu pozitif olan örneklere, laboratuvar içi tasarımla oluşturulan primerlerin kullanıldığı PCR yöntemi uygulanarak, ileriki çalışmalarda geliştirilmesi 
planlanan laboratuvar yapımı tüberküloz tanı kitinde kullanımının uygun olup olmadığı araştırılmıştır. Bu amaçla seçilen 100 kültür pozitif örneğe laboratuvar içi tasarımlı PCR yöntemi uygulanmışır. Bu örneklerin 98'inde kültür ile uyumlu pozitif sonuç elde edilirken, iki örnekte M.tuberculosis DNA'sı saptanmamıştır. Çalışma sonucunda Anyplex MTB/NTM testinin rutin tüberküloz tanısında kullanılabilecek hızlı, pratik ve güvenilir bir test olduğu sonucuna varılmıştır. Laboratuvar içi tasarıma sahip primerlerin kullanıldığı PCR yönteminin ön değerlendirme sonuçlarının rutinde kullanılan yöntemlerle uyumlu çıkması, daha uygun maliyetli yerli üretim tüberküloz moleküler tanı kitlerinin geliştirilmesine ışık tutacaktır. Böylece rutin tanı laboratuvarlarında hızı tanının, daha uygun maliyetle gerçekleştirilmesi mümkün olacaktır.

Anahtar kelimeler: Mycobacterium tuberculosis; tüberküloz; Anyplex MTB/NTM testi; laboratuvar içi tasarımlı PCR.

\section{ABSTRACT}

One of the most important steps for the control of tuberculosis is rapid and accurate detection of Mycobacterium tuberculosis in clinical samples. The early and accurate diagnosis of tuberculosis allows the initiation of the effective treatment regimen as early as possible. However the early diagnosis of tuberculosis can be achieved by the integration of molecular methods into the diagnostic algorithm of tuberculosis together with the gold standard culture methods. For this reason, molecular methods have become valuable diagnostic tools in routine diagnostic laboratories in recent years. The aim of this study was to determine the diagnostic efficacy of Anyplex MTB/NTM test (Seegene, South Korea) used for the molecular diagnosis of tuberculosis in routine molecular diagnostic laboratories. In addition to this aim, a preliminary evaluation of in-house polymerase chain reaction (PCR) primers that was designed to produce a kit as an alternative against imported commercial kits was performed. Ten thousand six hundred fifthy two clinical specimens that were collected from suspected tuberculosis cases in three years were included in the study. All samples were tested by microscopic examination after staining, culture and real-time PCR (Rt-PCR) methods. The smears were examined by microscope after staining with Kinyoun method for the existence of acid resistant bacilli. For culture, following the $\mathrm{N}$-acetyl-L-sistein-sodium hydroxide homogenization and decontamination procedure, the samples were inoculated into the MGIT (Mycobacteria Growth Indicator Tube) tubes (Becton Dickinson, USA). Rt-PCR method was performed by using Anyplex MTB/NTM test. In the first stage of the study, the performance of the Anyplex MTB/NTM test was compared with the gold standard culture method. M.tuberculosis was isolated in 178 specimens out of $10.652(1.7 \%)$. After the comparison with the gold standard culture method, the sensitivity and specificity of Anyplex MTB/NTM test was found to be $84 \%$ and $99 \%$ respectively in pulmonary samples, and $74 \%$ and $99 \%$ respectively in extrapulmonary samples. In the second stage of the study, PCR method with laboratory designed primers was applied to 100 culture positive samples. The PCR results of 98 samples were found to be in agreement with the culture, while M.tuberculosis DNA was not detected in two samples. As a result of the study it was concluded that Anyplex MTB/NTM test is a rapid, practical and reliable method that can be used in routine tuberculosis diagnosis. The high agreement between PCR method using the laboratory-designed primers and the PCR method used in routine practice will lighten the way for the development of national tuberculosis molecular diagnostic kits with a relevant cost. In this way, it will be possible to perform rapid diagnosis in a more cost-effective manner in routine diagnosis laboratories.

Keywords: Mycobacterium tuberculosis; tuberculosis; Anyplex MTB/NTM test; in-house PCR.

\section{Giriş}

Tüberküloz dünya genelinde, halen ilk 10 ölüm nedeni arasında kalmaya devam etmekte ve ölüme neden olan enfeksiyon etkenleri arasında da birinci sırada bulunmaktadır ${ }^{1}$. Tüberküloz nedeniyle gerçekleşen ölümlerin 2017 yılında 1.3 milyon civarında olduğu tahmin edilmektedir. Toplam 10 milyon insanın 2017 yılında tüberküloza yakalandığı bilinmektedir. Bunun yaklaşık bir milyonunu çocukluk çağındaki bireyler oluşturmakta- 
dır ${ }^{1}$. Bu nedenlerle tüberküloz, yıllardan beri Dünya Sağlık Örgütü (DSÖ)’nün öncelikli mücadele listesinde yer almaktadır. Bu mücadele kapsamında DSÖ 2014 yılında hedefi yükselterek, tüberküloz epidemisini 2030 yılı itibariyle sona erdirme stratejisini başlatmıştır. Bu stratejinin hedefleri, 2015 yılı verileri ile kıyaslandığında, tüberküloz nedeniyle gerçekleşen ölüm sayılarını \%90 oranında azaltmak ve tüberküloz insidansında \%80 azalma sağlamaktır. Bu nedenle tüberkülozun etkin kontrolü büyük önem taşımaktadır.

Tüberkülozun etkin kontrolündeki en önemli basamaklardan biri, klinik örneklerden Mycobacterium tuberculosis'in hızlı ve doğru bir şekilde saptanabilmesidir. Tüberkülozun laboratuvar tanı algoritmasında vazgeçilmez yöntemler olan mikroskobik inceleme ve altın standart kültür yöntemlerine son yıllarda, hızlı sonuç alınan moleküler yöntemler de eklenmiştir. Günümüzde rutin tüberküloz tanı laboratuvarlarında kullanılmakta olan çok sayıda farklı ticari veya laboratuvar içi tasarıma sahip moleküler test bulunmaktadır ${ }^{2-5}$.

Anyplex MTB/NTM testi (Seegene, Güney Kore), gerçek zamanlı polimeraz zincir reaksiyonu (Rt-PCR) yöntemi kullanılarak klinik örneklerde M.tuberculosis kompleksi ve tüberküloz dışı mikobakterilerin (NTM: non-tuberculosis mycobacteria) varlığını saptamak amacıyla geliştirilmiş bir testtir ${ }^{6,7}$. Bu testte M.tuberculosis kompleksi için hedef bölge IS6110 ve MPB64 genleri, NTM için hedef bölge ise 16S rRNA genidir.

$\mathrm{Bu}$ çalışmanın amacı, rutin moleküler tanı laboratuvarlarında klinik örneklerden M.tuberculosis saptanması amacıyla kullanılmakta olan Anyplex MTB/NTM testinin hızlı tanıdaki etkinliğinin araştırılmasıdır. Çalışma kapsamında yanı sıra, yurt dışı kökenli ticari kitlere alternatif olabilecek yerli kitler üretebilmek amacıyla tasarlanmış olan primerlerin PCR yöntemiyle ön değerlendirilmesinin yapılması hedeflenmiştir.

\section{GEREÇ ve YÖNTEM}

\section{Klinik Örnekler}

Bu çalışmaya, Ocak 2015-Ocak 2018 tarihleri arasındaki üç yıllık süreçte Hacettepe Üniversitesi Hastaneleri Merkez Laboratuvarına tüberküloz tanısı amacıyla yollanmış 10.652 klinik örnek dahil edildi.

\section{Mikroskobik İnceleme}

Hasta örneklerinden hazırlanan yayma örnekleri aside dirençli basil aranması amacıyla, Kinyoun boyama yöntemi ile boyandıktan sonra mikroskop ile incelendi.

\section{Kültür}

Tüm örneklere $\mathrm{N}$-asetil-L-sistein-sodyum hidroksit (NALC-NaOH) yöntemi ile homojenizasyon-konsantrasyon-dekontaminasyon işlemi uygulandı ${ }^{8}$. Bu amaçla her örnekten 5-10 ml'lik bir miktar, eşit hacimdeki NALC-NaOH çözeltisi ile karıştırılıp, 15 dakika oda sıcaklığında bekletildi. Daha sonra bu karışıma $30 \mathrm{ml}$ fosfat tamponu $(\mathrm{pH}=6.8)$ eklenerek $3000 \mathrm{xg}^{\prime}$ de 15 dakika santrifüj edildi. Santrifüj sonrasında elde edilen sediment $5 \mathrm{ml}$ fosfat tamponu ile sulandırıldı. Elde edilen bu örnek çözeltisinden MGIT şişelerine 
ve Löwenstein-Jensen besiyerine ekim yapılarak altı hafta süreyle $37^{\circ} \mathrm{C}$ 'de inkübasyona bırakıldı. Bu süre içinde üreme saptanan örneklere tüberküloz tanımlama testi (BD Diagnostics, ABD) uygulanarak M.tuberculosis kompleksi ile tüberküloz dışı mikobakterilerin ayrımı yapıldı ${ }^{9}$.

\section{Gerçek Zamanlı Polimeraz Zincir Reaksiyonu}

Hasta örneklerine uygulanan homojenizasyon-konsantrasyon-dekontaminasyon işlemi sonrasında, örneğin $1 \mathrm{ml}$ hacmindeki kısmı PCR için kullanılmak üzere ayrıldı. Rt-PCR yöntemi Anyplex MTB/NTM kiti kullanılarak CFX 96 Rt-PCR cihazında (Bio-Rad, ABD) gerçekleştirildi. PCR reaksiyon karışımı toplam $15 \mu \mathrm{l}^{\prime}$ lik hacimde $10 \mu \mathrm{l}$ Anyplex 2x master miks, $3 \mu \mathrm{l}$ metoksipsoralen (8-MOP) ve $2 \mu \mathrm{l}$ 10x M.tuberculosis/NTM oligonükleotit ile hazırlandı. Bu karışıma $5 \mu$ hedef DNA eklendi. Çoğaltma ve saptama işlemleri CFX 96 Rt-CR cihazında (Bio-Rad, ABD) gerçekleştirildi. Kit içeriğinde sağlanmış olan negatif kontrol, pozitif kontrol ve internal kontrol de örneklerle birlikte kullanıldı. Sonuçların değerlendirilmesi cihazın bilgisayar yazılımı kullanılarak yapıldı ${ }^{10}$.

\section{Laboratuvar içi Tasarımlı Primerler ile Gerçekleştirilen Polimeraz Zincir Reaksiyonu}

PCR için hedef olarak, M.tuberculosis kompleksi üyelerinde bulunan fakat tüberküloz dışı mikobakterilerde bulunmayan senX3-regX3 gen bölgesi seçildi ${ }^{11}$. 'Primer3' primer tasarım programı kullanılarak senX3-F 5'-CCG TCG GTG CCA TGG CTC TAC TC ve senX3-R 5'- GGA TGG TGC CGT CGT GAT TAG CC primerleri tasarlandı. Kalıp DNA'nın amplifikasyonu için $50 \mu l^{\prime}$ lik karışımlar hazırlandı. Bu karışım kalıp DNA ile birlikte özgül primer çiftinden 100'er pM, $1.25 \mathrm{U}$ Taq polimeraz, $50 \mathrm{mM} \mathrm{KCl}, 10 \mathrm{mM}$ Tris $\mathrm{pH}=8.3$, $1.25 \mathrm{mM} \mathrm{MgCl}_{2^{\prime}} 200 \mu \mathrm{M}$ dNTP karışımını içerecek şekilde hazırlandı. Tüplere termal döngü cihazında $94^{\circ} \mathrm{C}^{\prime}$ de 3 dakikalık denatürasyon sonrasında, $94^{\circ} \mathrm{C}^{\prime}$ de 3 dakika denatürasyon, $58^{\circ} \mathrm{C}^{\prime}$ de 45 saniye bağlanma ve $72^{\circ} \mathrm{C}^{\prime}$ de 1 dakika polimerizasyon işlemleri 45 döngü tamamlanacak şekilde uygulandı. En son aşamada $72^{\circ} \mathrm{C}^{\prime}$ de 3 dakikalık ek bir polimerizasyon basamağı eklenerek PCR işlemi tamamlandı. Elde edilen ürünler \%1.5 agaroz jel elektroforezi ile ayrıştırıldı ve etidyum bromür ile boyandıktan sonra ultraviyole ışığı varlığında incelendi. Agaroz jelde 567 baz çifti (bp) büyüklüğünde DNA parçası varlığı araştırıldı.

\section{BULGULAR}

Çalışmanın birinci aşamasında, tüberkülozun moleküler tanısında kullanılan Anyplex MTB/NTM testinin etkinliği, altın standart kültür yöntemiyle karşılaştırılarak değerlendirilmiştir. Çalışmaya dahil edilen toplam 10.652 örneğin 8319 (\%78)'u akciğer kökenli örnek, 2333 (\%22)'ü ise akciğer dışı örneklerden oluşmuştur. Örneklerin 178 (\%1.7)'inde altın standart kültür yöntemiyle M.tuberculosis üremesi saptanmıştır. Pozitif saptanan örneklerin 159 (\%89)'unun akciğer kökenli, 19 (\%11)'unun ise akciğer dışı örnek olduğu saptanmıştır. 
Akciğer kökenli örnekler incelendiğinde, kültürde pozitif saptanan 159 örneğin 134 (\%84)'ünün Anyplex MTB/NTM testi ile pozitif olarak saptandığı görülmüştür. Buna karşlık MGIT kültür yöntemi ile pozitif olarak saptanan 25 örnek Anyplex MTB/NTM testi ile negatif bulunmuştur. Dört örnekte ise MGIT kültür yöntemi ile üreme saptanmazken, Anyplex MTB/NTM testi ile pozitif sonuç elde edilmiştir (Tablo I).

Akciğer dışı örnekler incelendiğinde, kültürde pozitif saptanan 19 örneğin 14 (\%74)'ünün Anyplex MTB/NTM testi ile pozitif olarak saptandığı görülmüştür. Buna karşııı MGIT kültür yöntemi ile pozitif olarak saptanan beş örnek Anyplex MTB/NTM testi ile negatif bulunmuştur. İki örnekte ise MGIT kültür yöntemi ile üreme saptanmazken, Anyplex MTB/NTM testi ile pozitif sonuç elde edilmiştir (Tablo II).

Altın standart yöntem kabul edilen kültür yöntemiyle yapılan karşılaştırma sonucunda, Anyplex MTB/NTM Rt-PCR yönteminin duyarlılık ve özgüllüğü akciğer kökenli örneklerde sırasıyla \%84 ve \%99, akciğer dışı örneklerde ise sırasıyla \%74 ve \%99 olarak bulunmuştur.

Çalışmanın ikinci aşamasında ise, kültür sonucu pozitif olan örneklere, laboratuvar içi tasarımlı primerlerin kullanıldığı PCR yöntemi uygulanarak, ileriki çalışmalarda geliştirilmesi planlanan laboratuvar içi tasarıma sahip tüberküloz tanı kitinde kullanımının uygun olup olmadığı araştırılmıştır. Bu amaçla seçilmiş olan 100 kültür-pozitif örneğe laboratuvar içi tasarımlı PCR yöntemi uygulanmıştır. Bu örneklerin 98'inde kültür ile uyumlu pozitif sonuç elde edilirken iki örnekte M.tuberculosis DNA'sı saptanamamıştır.

Tablo I. Akciğer Kökenli Örneklerden Mycobacterium tuberculosis Saptanmasında MGıT Kültür Yöntemi ile Anyplex MTB/NTM Rt-PCR Yönteminin Karşılaştırılması

\begin{tabular}{llccc}
\hline & & \multicolumn{3}{c}{ Anyplex MTB/NTM } \\
\cline { 3 - 5 } Yöntem & & Pozitif & Negatif & Toplam \\
\hline MGIT & Pozitif & 134 & 25 & 159 \\
& Negatif & 4 & 8156 & 8160 \\
& Toplam & 138 & 8181 & 8319 \\
\hline & & & \\
\end{tabular}

Tablo II. Akciğer Dışı Örneklerden Mycobacterium tuberculosis Saptanmasında MGıT Kültür Yöntemi ile Anyplex MTB/NTM Rt-PCR Yönteminin Karşılaştırılması

\begin{tabular}{llccc}
\hline & & \multicolumn{3}{c}{ Anyplex MTB/NTM } \\
\cline { 3 - 5 } Yöntem & & Pozitif & Negatif & Toplam \\
\hline MGIT & Pozitif & 14 & 5 & 19 \\
& Negatif & 2 & 2312 & 2314 \\
& Toplam & 16 & 2317 & 2333 \\
\hline & & & \\
\end{tabular}




\section{TARTIŞMA}

Tüberkülozun laboratuvar tanısında altın standart olarak kabul edilen yöntem kültür yöntemidir. Özellikle sıvı bazlı yarı otomatize veya tam otomatize kültür sistemleri ile konvansiyonel kültür yöntemlerine göre daha kısa sürede sonuç elde edilebilmesi bu sistemlerin yaygın olarak kullanılmasını sağlamaktadır ${ }^{12}$. Tüberküloz tanısının 1-2 gün gibi kısa bir sürede konabilmesi hem tedaviye erken başlanabilmesini hem de bu hastalarla temasa bağlı yeni olguların önlenebilmesi açısından büyük önem taşımaktadır. Özellikle dirençli olgu sayısındaki artış nedeniyle, tedaviye bir an önce başlayabilmek ve bulaşa bağlı olası yeni olguları önleyebilmek amacıyla, duyarlılığı ve özgüllüğü yüksek, hızlı sonuç veren, uygulaması kolay ve pahalı olmayan laboratuvar yöntemlerinin günlük kullanıma girmesi önemli bir gereksinim haline gelmiştir ${ }^{13}$. Moleküler mikrobiyolojik yöntemler bu ihtiyacı karşılayabilmek amacıyla geliştirilmeye başlanmış ve günümüzde tüberkülozun laboratuvar tanısında büyük önem taşıyan hızlı ve güvenilir tanı araçları haline gelmiştir ${ }^{14-16}$.

Bu çalışmada, rutin moleküler tanı laboratuvarımızda klinik örneklerden M.tuberculosis saptanması amacıyla kullanılmakta olan Anyplex MTB/NTM testinin tüberküloz tanısına olan katkısı araştırılmıştır. Altın standart olarak kabul edilen MGIT kültür yöntemiyle yapılan karşılaştırma sonucunda, Anyplex MTB/NTM Rt-PCR testinin duyarlılık ve özgüllüğü akciğer kökenli örneklerde sırasıyla \%84 ve \%99, akciğer dışı örneklerde ise sırasıyla \%74 ve \%99 olarak bulunmuştur.

Tüberküloz tanısında kullanılan moleküler yöntemlerin özgüllükleri, yapılan birçok çaıışmada yüksek bulunmasına karşın, duyarlılıkları konusunda uygulanan teste göre oldukça değişik sonuçlar elde edilebilmektedir ${ }^{17,18}$. Farklı duyarlılık sonuçları elde edilmesinde, kullanılan PCR yönteminin yanı sıra, örnek türü ve örnek içindeki basil miktarı da önemli rol oynamaktadır. Klinik örneklere homojenizasyon-dekontaminasyon işleminin uygulanması sırasında basillerin kaybedilmesi, örnek içinde yöntemin yalancı negatifliğine neden olan inhibitör maddeler bulunması veya M.tuberculosis DNA'sının etkin bir şekilde açığa çıkarılamaması da yöntemin duyarlılık sonuçlarını etkileyebilmektedir.

Perry ve arkadaşları ${ }^{10}$ Anyplex MTB/NTM testini kültür yöntemiyle kıyasladıkları çalışmada duyarlılık ve özgüllüğü sırasıyla \%86 ve \%99 olarak bulmuşlardır. Üç yıllık süre içerisinde toplam 110 klinik örneğin dahil edildiği çalışma sonucunda Anyplex MTB/NTM testinin düşük tüberküloz insidanslı bölgelerde mikroskobik incelemenin yerini alabilecek ve rutin tanıda kullanılabilecek bir test olduğu sonucuna varılmıştır. Bizim çalışmamızda klinik örnek sayısı çok yüksek olup üç yıllık süre içerisinde kültür yöntemi ile tüberküloz pozitiflik oranı \%1.7 seviyesinde saptanmıştır. Hastanemizde çalışılan klinik örnekler içinde tüberküloz kültür sonucunun düşük pozitiflik oranına sahip olmasının nedeni, çoğunlukla laboratuvara tüberküloz tanısının dışlanması amacıyla örnek gönderilmesi, akciğer dışı örnek sayısının fazla olması, tüberküloz şüphesi bulunan hastaların çoğunlukla Göğüs Hastalıkları Hastanelerine başvurması veya yönlendirilmesi gibi nedenlerle gerçekleştiğini 
düşünmekteyiz. Düşük tüberküloz kültür pozitiflik oranına sahip merkezlerde kullanılacak olan moleküler yöntemin seçiminde, ilaç direncine neden olan mutasyonları saptamaksızın klinik örneklerde sadece M.tuberculosis kompleksini saptayan testlerin kullanılması daha uygun maliyetli bir seçenek sağlayabilir. Gelişen teknoloji ile birlikte son yıllarda klinik örneklerde aynı anda hem M.tuberculosis kompleksi varlığını, hem de ilaç direncine neden olan mutasyonları saptayabilen moleküler yöntemler rutin kullanıma girmeye başlamıştır $^{19-21}$. Daha yüksek maliyetli olan bu testler özellikle yüksek insidanslı bölgelerde hem tanının erken konabilmesi, hem de ilaç direncinin erken dönemde saptanabilmesi açısından çok değerli testler haline gelmiştir. Günümüzde bu testler düşük tüberküloz insidansına sahip bölgelerdeki merkezlerde de giderek artan yaygınlıkta rutin kullanıma girmeye başlamıştır. Ancak çok düşük insidanslı bölgelerde, sadece M.tuberculosis kompleksi varlığını test eden daha uygun maliyetli yöntemlerin seçilmesi; bu yöntemle pozitif saptanan örneklere, gecikmeden moleküler direnç testlerinin uygulanması alternatif bir algoritma olarak önerilebilir.

Bu alternatif algoritma üzerinden yola çıkılarak çalışmamız kapsamında ayrıca, yurt dışı kökenli ticari kitlere alternatif olabilecek uygun maliyetli yerli üretim kit üretebilmek amacıyla bir ön deneme çalışması gerçekleştirilmiştir. Bu amaçla laboratuvar içi tasarıma sahip PCR primerleri 100 adet kültür pozitif klinik örnekte test edilmiştir. Bu örneklerin 98'inde kültür ile uyumlu pozitif sonuç elde edilirken, iki örnekte negatif sonuç elde edilmiştir. PCR için seçilen senX3-regX3 gen bölgesi, iki parçalı bir düzenleyici sistemden oluşmakta ve algılayıcı kısım olan senX3 bir histidin kinaz olup özgül uyarılara yanıt vermektedir. Düzenleyici kısım olan regX3 ise uyarılma sonrasında belirli genlerin ekspresyonunu kontrol edebilme özelliğine sahiptir. Algılayıcı protein uyarım sonrasında otofosforilizasyona uğramakta ve sonrasında bu fosfat, düzenleyici proteine transfer edilmektedir. Düzenleyici, DNA bağlayan bir proteindir ve gen ekspresyonunu arttırıp azaltabilmektedir ${ }^{22,23}$.

Sanjuan-jimenez ve arkadaşları ${ }^{24}$ moleküler yöntemlerin tüberküloz tanısındaki etkinliğini araştırdıkları çalışmada, senX3-regX3 gen bölgesini hedefleyen PCR yöntemiyle, IS6110 gen bölgesini hedefleyen farklı PCR yöntemlerini karşılaştırmışlardır. Yüz kırk beş klinik örneğin dahil edildiği çalışma sonucunda senX3-regX3 PCR yöntemi ile \%85.5 duyarlıık, \%100 özgüllük elde etmişler ve bu yöntemin rutin moleküler tanıda kullanılabilecek alternatif bir yöntem olabileceği sonucuna varmışlardır.

Bizim çalışmamızda kullanılan ve senX3-regX3 gen bölgesini hedefleyen laboratuvar tasarımı primerlerle ümit verici sonuçlar elde edilmesi, bundan sonraki çalışmalar için yol gösterici olacaktır. Aynı gen bölgesinin farklı bölümlerini hedef alan Rt-PCR primer ve prob tasarımı sonrasında daha pratik ve hızlı bir yöntemin geliştirilebilmesi mümkün görünmektedir. Hedef gen bölgesi olarak özellikle senX 3 ve regX 3 genleri arasında kalan ve promotor aktivitesi olduğu düşünülen bölgenin seçilmesi planlanmaktadır. Böylece yaygın olarak kullanılan IS6110 ve 16S rRNA hedef bölgelerine iyi bir alternatif geliştirilebileceği ümit edilmektedir. 
Bu çalışma sonucunda Anyplex MTB/NTM testinin rutin tüberküloz tanısında kullanılabilecek hızlı, pratik ve güvenilir bir test olduğu sonucuna varılmıştır. Laboratuvar tasarımı primerlerin kullanıldığı PCR yönteminin ön değerlendirme sonuçlarının rutinde kullanılan yöntemlerle uyumlu çıkması, daha uygun maliyetli yerli üretim tüberküloz moleküler tanı kitlerinin geliştirilmesine ışık tutacaktır. Böylece rutin tanı laboratuvarlarında tüberküloz tanısında hızlı tanı amacına daha uygun maliyetle ulaşılabilmesi hedeflenmektedir.

\section{ÇIKAR ÇATIŞMASI}

Yazarlar bu makale ile ilgili herhangi bir çıkar çatışması bildirmemişlerdir.

\section{KAYNAKLAR}

1. Global tuberculosis report 2018. Geneva: World Health Organization, 2018.

2. Drobniewski F, Nikolayevskyy V, Maxeiner H, Balabanova Y, Casali N, Kontsevaya I, et al. Rapid diagnostics of tuberculosis and drug resistance in the industrialized world: clinical and public health benefits and barriers to implementation. BMC Medicine 2013;11:190.

3. Denkinger CM, Kik SV, Cirillo DM, Casenghi M, Shinnick T, Weyer $K$, et al. Defining the needs for next generation assays for tuberculosis. J Infect Dis 2015;211(Suppl 2):S29-38.

4. Nurwidya F, Handayani D, Burhan E, Yunus F. Molecular diagnosis of tuberculosis. Chonnam Med J 2018;54(1):1-9.

5. Forbes BA, Hall GS, Miller MB, Novak SM, Rowlinson MC, Salfinger M, et al. Practice guidelines for clinical microbiology laboratories: Mycobacteria. Clin Microbiol Rev 2018;31(2). pii: e00038-17.

6. Lim JH, Kim CK, Bae MH. Evaluation of the performance of two real-time PCR assays for detecting Mycobacterium species. J Clin Lab Anal 2019;33(1):e22645.

7. Mpanyane DM, Maguga-Phasha TNC, Mashinya F, Malinga LA. The diagnostic utility of Anyplex Plus MTB/ NTM cycle threshold for detection of Mycobacterium tuberculosis complex among new and retreatment cases from a referral hospital in Limpopo Province, South Africa. Biomed Biotechnol Res J 2017;1:141-6.

8. Yajko DM, Nassos PS, Sanders CA, Gonzalez PC, Reingold AL, Horsburgh Jr CR, et al. Comparison of four decontamination methods for recovery of Mycobacterium avium complex from stools. I Clin Microbiol1993;31:302-6.

9. Yu MC, Chen HY, Wu MH, Huang WL, Kuo YM, Yu FL, et al. Evaluation of the rapid MGIT TBc identification test for culture confirmation of Mycobacterium tuberculosis complex strain detection. J Clin Microbiol 2011;49:802-7.

10. Perry MD, White PL, Ruddy M. Potential for use of the Seegene Anyplex MTB/NTM real-time detection assay in a regional reference laboratory. J Clin Microbiol 2014;52(5):1708-10.

11. Parish T, Smith DA, Roberts G, Betts J, Stoker NG. The senX3-regX3 two-component regulatory system of Mycobacterium tuberculosis is required for virulence. Microbiology 2003;149(Pt 6):1423-35.

12. Rageade F, Picot N, Blanc-Michaud A, Chatellier S, Mirande C, Fortin E, et al. Performance of solid and liquid culture media for the detection of Mycobacterium tuberculosis in clinical materials: meta-analysis of recent studies. Eur J Clin Microbiol Infect Dis 2014;33:867-70.

13. Auld SC, Kasmar AG, Dowdy DW, Mathema B, Gandhi NR, Churchyard GJ, et al. Research roadmap for tuberculosis transmission science: Where do we go from here and how will we know when we're there? J Infect Dis 2017;216(Suppl 6):S662-68.

14. Harries AD, Kumar AMV. Challenges and progress with diagnosing pulmonary tuberculosis in low- and middle-income countries. Diagnostics (Basel) 2018;pii:E78.

15. Eddabra R, Benhassou HA. Rapid molecular assays for detection of tuberculosis. Pneumonia (Nathan) 2018;10:4. 
16. Mbelele PM, Mohamed SY, Sauli E, Mpolya EA, Mfinanga SG, Addo KK, et al. Meta-narrative review of molecular methods for diagnosis and monitoring of multidrug-resistant tuberculosis treatment in adults. Int J Mycobacteriol 2018;7(4):299-309.

17. Akkerman OW, van der Werf TS, de Boer M, de Beer JL, Rahim Z, Rossen JW, et al. Comparison of 14 molecular assays for detection of Mycobacterium tuberculosis complex in bronchoalveolar lavage fluid. J Clin Microbiol 2013;51:3505-11.

18. Gürsoy NC, Yakupoğulları Y, Tekerekoğlu MS, Otlu B. Klinik örneklerde Mycobacterium tuberculosis'in saptanması ve rifampin direncinin tespitinde Xpert MTB/RIF testinin tanısal performansının değerlendirilmesi. Mikrobiyol Bul 2016;50(2):196-204.

19. Özkütük N, Sürücüoğlu S. Orta prevalanslı bölgede akciğer ve akciğer dışı tüberküloz tanısında Xpert MTB/ RIF testinin değerlendirilmesi. Mikrobiyol Bul 2014;48:223-32.

20. Igarashi Y, Chikamatsu K, Aono A, Yi L, Yamada H, Takaki A, et al. Laboratory evaluation of the Anyplex ${ }^{T M}$ II MTB/MDR and MTB/XDR tests based on multiplex real-time PCR and melting-temperature analysis to identify Mycobacterium tuberculosis and drug resistance. Diagn Microbiol Infect Dis 2017;89:276-81.

21. Perez-Garciaa F, Ruiz-Serranoa MJ, Roa PL, Acosta F, Pérez-Lago L, García-De-Viedma D, et al. Diagnostic performance of Anyplex II MTB/MDR/XDR for detection of resistance to first and second line drugs in Mycobacterium tuberculosis. J Microbiol Methods 2017;139:74-8.

22. Glover RT, Kriakov J, Garforth SJ, Baughn AD, Jacobs Jr WR. Mycobacterium smegmatis phosphate-dependent gene expression in senX3-regX3 regulates the two-component regulatory system. J Bacteriol 2007; 189:5495503.

23. Bretl DJ, Demetriadou C, Zahrt TC. Adaptation to environmental stimuli within the host: two-component signal transduction systems of Mycobacterium tuberculosis. Microbiol Mol Biol Rev 2011;75:566-82.

24. Sanjuan-jimenez R, Toro-Peinado I, Bermudez P, Colmenero JD, Morata P. Comparative study of a real-time PCR assay targeting senX3-regX3 versus other molecular strategies commonly used in the diagnosis of tuberculosis. PLoS One 2015; 10:e0143025. 